\title{
BONE LESIONS DUE TO SMALLPOX
}

\author{
BY \\ R. EECKELS, J. VINCENT*, and V. SEYNHAEVE \\ From the Departments of Paediatrics and Anatomy, Lovanium University, Léopoldville, Congo Republic
}

(RECEIVED FOR PUbliCATION JANUARY 14, 1964)

During the autumn of 1961 and the first months of 1962, an extensive outbreak of smallpox occurred in the Léopoldville area of the Republic of the Congo. In several hospitals of Léopoldville and its surroundings, a number of smallpox cases in young children was seen presenting the same type of skeletal complications. They consisted of a bilateral, symmetrical osteomyelitis with arthritis. The usual sites of these lesions were, in order of frequency, the forearms, including elbows and wrists, and the legs, including knees and ankles.

Generalized lesions of the skeleton appearing during the recovery period from the smallpox eruption have been described under the name of 'osteomyelitis variolosa'. It has been suggested that they are due to the direct action of the smallpox virus on the skeleton. The clinical and radiological features of osteomyelitis variolosa have recently been the subject of a thorough review by Cockshott and MacGregor $(1958,1959)$. The histological data on this condition are, however, very scanty.

We report three cases of osteomyelitis variolosa in which we had the opportunity of performing a histological study of bone.

\section{Case Reports}

Case 1. A girl aged 2 years 7 months was admitted at the Lovanium University Hospital on March 30, 1962.

On February 19, 1962, she had been admitted to another hospital with smallpox in the pustular stage. On February 27, while her skin lesions were healing satisfactorily, a diffuse painful swelling of the left elbow was noted. Successively, the right elbow, both wrists, knees, and ankles became swollen and tender. When walking became impossible, the child was brought to the Lovanium Hospital.

Examination disclosed a little girl of Bantu race with depigmented pockmarks on the whole body (Fig. 1). Axillary temperature $37 \cdot 3^{\circ} \mathrm{C}$. There was a marked swelling with fluid accumulation in both elbows and ankles. The wrists and knees were also swollen to a

\footnotetext{
- Dr. Jacques Vincent died on June 9. 1964.
}

lesser degree. All these joints were very tender and movements were limited.

Haemoglobin was $7 \cdot 35 \mathrm{~g} . / 100 \mathrm{ml}$.; red blood cells numbered 1,980,000/c.mm.; white blood cells $4,950 / \mathrm{c} . \mathrm{mm}$. with $44^{\circ} \%$ polymorphonuclear leukocytes, $2 \%$ eosinophils, $53 \%$ lymphocytes, and $1 \%$ monocytes. The thick drop was positive for $P$. falciparum. The sickling test was negative. Paper electrophoresis of the haemoglobin showed only haemoglobin A.

The urine contained no protein, sugar, or deposit. The stools contained eggs of Ancylostoma duodenale and Ascaris lumbricoides.

A Widal test and a tuberculin skin test remained negative.

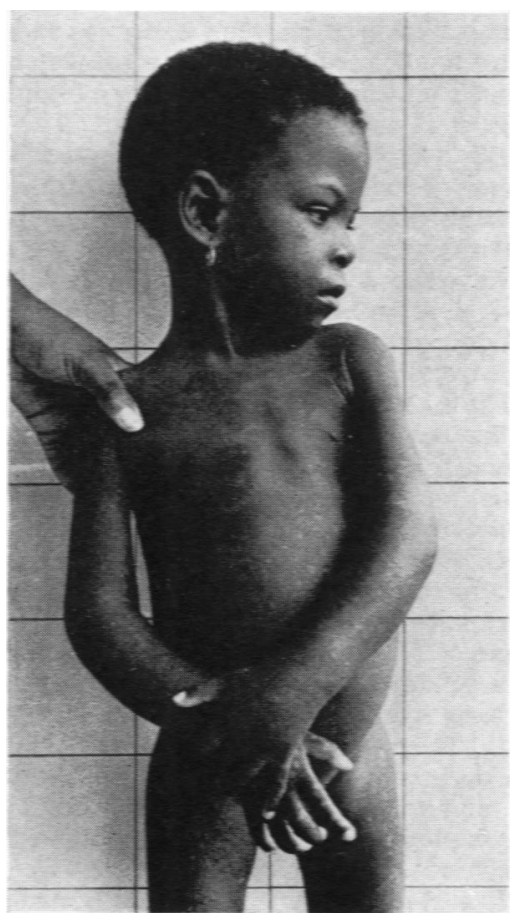

Fig. 1.-Case 1: the depizmented pockmarks and the swollen elbows are shown. 
Treatment consisted of blood transfusion, chloroquine, bephenium hydroxynaphthoate, and an oral iron preparation.

The child's general condition improved rapidly. Temperature remained normal. On April 2, the involved joints seemed to be somewhat less painful. This became more obvious on April 10, when the knees could be moved without undue difficulty. On April 12, an aspiration of the right elbow yielded $3 \mathrm{ml}$. blood-tinged serous fluid, and a bone fragment was also excised at the proximal metaphysis of the right ulna.

On April 20, the knees were clinically normal. Limited passive movements became possible at the wrists, elbows, and ankles, which were all swollen. Crepitations were felt at both wrists and at the right elbow. The child could walk about now very cautiously.

During the following weeks, clinical symptoms regressed slowly. Some swelling of the joints persisted. but the pain subsided completely and the functional incapacity disappeared. On discharge on May 5, she could move freely but still showed some articular swelling. The same condition was found at a follow-up visit on May 25, three months after the first complaints.

Case 2. A girl aged 2 years 2 months was admitted at the Lovanium University Hospital on March 19, 1963. She had had smallpox in the first half of February 1963. At the beginning of March, when the smallpox lesions had almost disappeared, a painful swelling of both elbows appeared. In the next few days, the wrists, ankles, and knees became involved, showing tenderness and swelling.

Examination showed a little Bantu girl with numerous depigmented pockmarks. She was very frightened ard seemed in great pain when manipulated. The temperature was $37 \cdot 2^{\circ} \mathrm{C}$. Both elbows, wrists, ankles, and knees were grossly swollen and very tender. Intra-articular fluid probably present. There was no spontaneous pain. The forearms were kept in flexion. Passive movements of the involved joints were possible but very painful.

$\mathrm{Hb} 7.8 \mathrm{~g} .100 \mathrm{ml}$.; red blood cells $2,450,000 / \mathrm{c} . \mathrm{mm}$.; white blood cells $10,000 /$ c.mm. with $62^{\circ}$ o polymorphonuclear leucocytes, $1^{\circ}$ o cosinophils, and $37^{\circ} \mathrm{o}$ lymphocytes. The thick drop was negative for malaria parasites. The sickling test was negative and paper electrophoresis of the haemoglobin showed only haemoglobin A. The urine was normal. The stools contained eggs of Ancylostoma duodenale and larvae of Strongyloides stercoralis.

Treatment consisted of blood transfusion, bephenium hydroxynaphthoate, and dithiazanine. A trial of prednisone (25 mg./day) combined with dimethylchlortetracycline was given from April 12 to May 15.

From early April, the swelling of the knees and ankles regressed. The swelling of the wrists and elbows began to recede during the second half of the same month. On April 6, the upper third of the medial aspect of the left tibia was explored surgically. From under the periosteum, which was clearly thickened, $2 \mathrm{ml}$. turbid fluid was aspirated: a bone biopsy was also performed. At the end of April, all articular swellings were receding. Passive movements were now painless. Extension of the elbows was slightly limited. The child was beginning to walk cautiously.

In May, a gradual increase in radial deviation of both hands was noted, together with a clear-cut progression of the ankylosis of both elbows. Feet and knees were now normal. In August, the radial deviation of both hands reached about $20^{\circ}$ and a resection of the distal extremities of both ulnae was undertaken. Recovery was uncomplicated. The results of the intervention were satisfactory, the hands being placed again in line with the forearms, and functioning normally. From September onward the process stabilized, leaving as a sequel a partial ankylosis of the elbows.

Case 3. A boy aged 6 years was admitted at the Lovanium University Hospital on June 4, 1963. In March, 1962, he had had smallpox and was treated in another hospital. Back home, his two forearms and legs began to swell. After a certain time, the parents noticed that the child had more and more difficulty in flexing the arms. When this became a severely limiting factor in the child's movements, he was brought to the Lovanium Hospital.

Examination showed a boy of Bantu race in good general condition and presenting a gross swelling of both arms and legs. The skin showed faint pockmarks. There was a distinct fusiform swelling around the elbows. The legs and forearms were swollen, but there was no oedema. All joints moved freely, except for the elbous. The arms were flexed at the elbow's at an angle of $40^{\circ}$ and movements of flexion and extension were limited to about $15^{\text {* }}$ in both directions.

Haemoglobin $9 \cdot 1$ g. $/ 100 \mathrm{ml}$. Sickling test was negative. A thick drop was negative for malarial parasites. Urine normal. The stool contained eggs of Ascaris lumbricoides, Ancylostoma duodenale, and larvae of Strongyloides stercoralis.

Treatment consisted of bephenium hydroxynaphthoate, piperazine citrate, and ferrous sulphate.

On June 20, resection of the ankylosed left elbow: joint was undertaken. A piece of the resected olecranon was taken for biopsy. One month after the intervention results were disappointing, for owing to the formation of an osteoma there was no gain in mobility. It was decided to delay further surgery until the child was old enough to participate more actively in his postoperative re-education.

\section{Bacteriological and Virological Examinations}

The fluids withdrawn from the right elbow joint in Case 1, and aspirated from the subperiosteal layer of the left tibia in Case 2, were submitted for bacteriological and virological examinations. Microscopic examination of the stained sediment was negative. Cultures on broth, blood-agar, and McConckey-agar remained sterile. Inoculation on chorioallantoic membrane (Case 1), and chorioallantoic membrane and tissue cultures (Case 2), revealed no virus.

\section{Radiological Examinations}

In the first two cases, a radiological survey of the complete skeleton was carried out on admission. The 


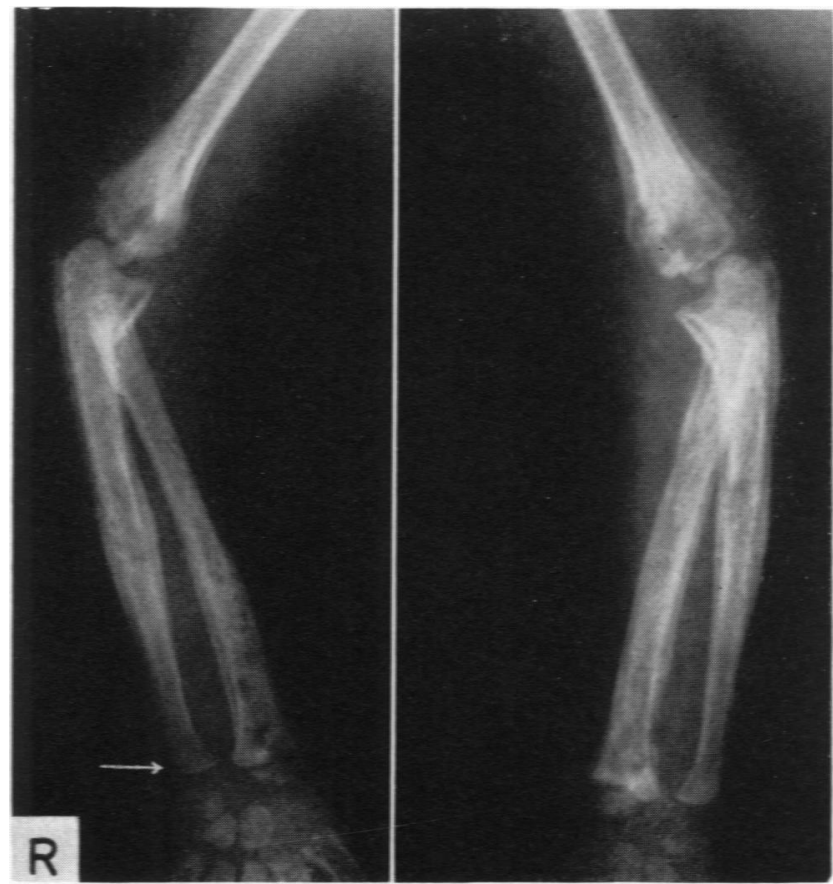

Fig. 2.-Case 1 : generalized periostitis and patchy destruction of the diaphyses. A narrow band of transverse metaphysitis is indicated by the arrow.

lesions were very similar in both patients. All existing lesions were strikingly symmetrical and localized to the distal parts of the humeri, the radii, ulnae, and metacarpals, and the tibiae, fibulae, and metatarsals. The other bones were normal.

The first radiographs of Cases 1 and 2, taken respectively one month and three weeks after the beginning of the articular symptoms, showed the following lesions.

(a) A generalized and very severe periosteal reaction along the shaft of all the involved long bones. In some places the thickened periosteum seemed lifted up, having lost its contact with the underlying bone (Figs. 2 and 3).

(b) Multiple areas of patchy destruction, especially at the distal metaphysis of the long bones around wrists and ankles. This was very conspicuous in Case 1 (Fig. 2), where clear-cut, rounded defects were visible, eroding the cortex in some places. Patchy destruction existed also in the shafts, but to a lesser degree.

(c) A narrow band of translucency, underlying the cartilaginous plate of some metaphyses (Fig. 2). At the proximal end of some metacarpals, where no metaphysial zone exists, a broader transverse destruction could also be seen (Fig. 4).

(d) Possible early epiphysial destruction was visible in a few places (Fig. 4).

The further evolution can be seen on a radiograph of Case 2, taken four months after the first complaints (Fig. 5). It shows (a) a diminution of the periosteal

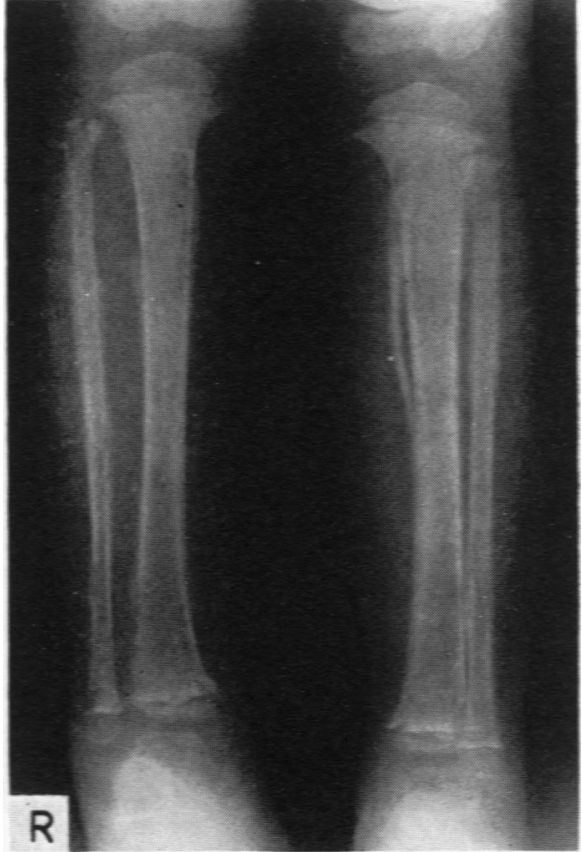

Fig. 3. - Case 2: the periosteal reaction is very conspicuous. Loss of contact between thickened periosteum and cortex. The shafts are less involved than in Case 1. 


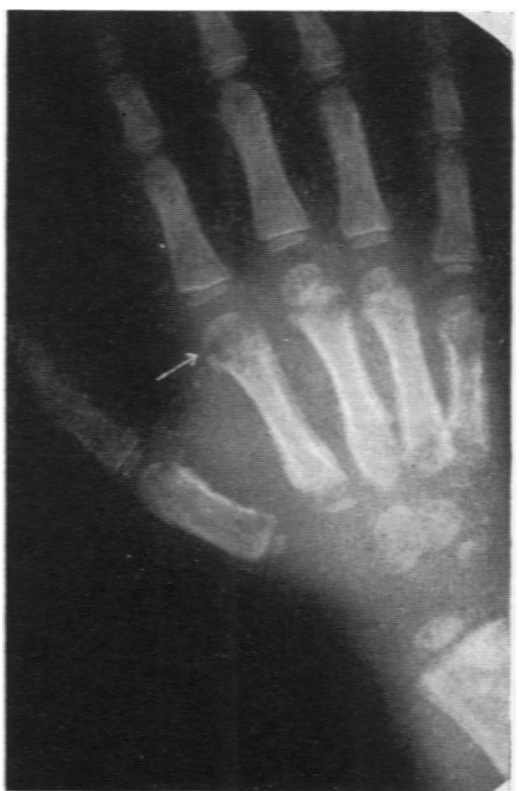

Fig. 4.-Case 1 : periosteal reaction of the metacarpals of the hand. Transverse destruction at the proximal end of some of the metacarpals. Epiphysial kesion shown by arrow.

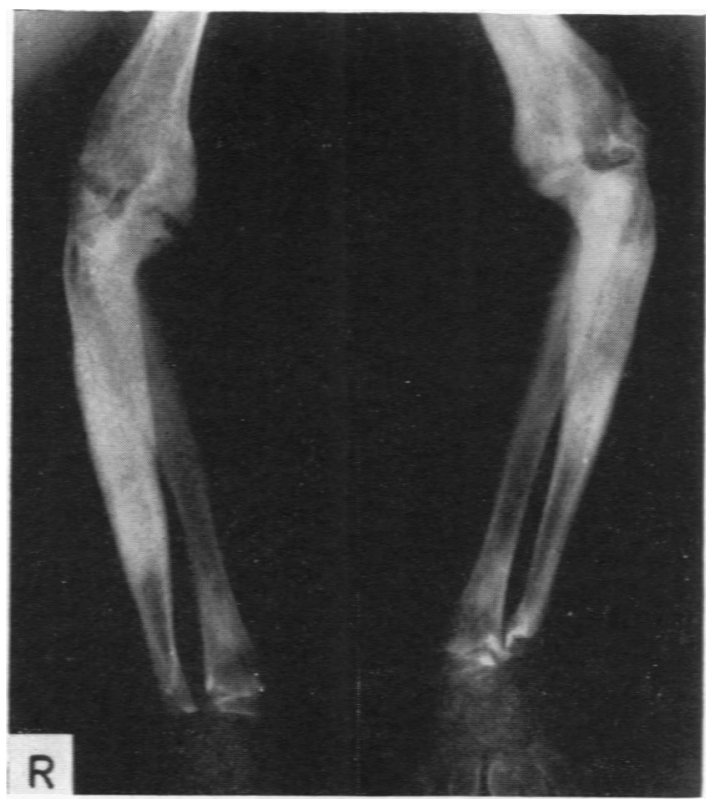

FK. 6.-Case 3: irregular opacification. especially of both ulnae. Ankylosis of the elbows. A small sequestrum is present in the midportion of the left ulna. The distal ulnar epiphyses have disappeared, and the distal end of the left ulna is distorted.

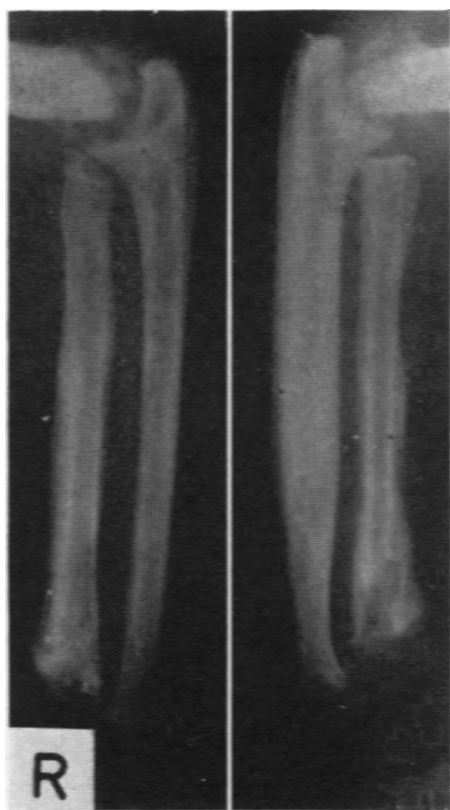

F1G. 5.-Case 2: increased opacity of the bones and complete destruction of the epiphysial and metaphysial zones of both radii. The lamellated appearance of the periosteum is barely visible on this reproduction.

reaction; the still thickened periosteum is becoming more dense, and presents a lamellated appearance; (b) an over-all densification of the whole bone, which presents a massive, thickened appearance; (c) striking progression of the epiphysial and metaphysial destruction. It is to be noted that this did not exist in Case 1, though it showed the more severe initial lesions.

In Case 3, radiographs taken 15 months after the first symptoms still show a generalized and irregular opacification with severe epiphysial and metaphysial lesions, giving rise to bilateral ankylosis of the elbow joints (Fig. 6).

\section{Histology}

Each biopsy specimen was divided in two parts. One sample was fixed in $96^{\circ}$ o ethanol or in neutral formalin and then embedded in methylmethacrylate. Sections 50 if thick obtained with the Gillings-Hamco Thin Sectioning Machine were radiographed.

The other sample of each specimen was fixed in Bouin's fhuid or in neutral formalin, decalcified in a $5 \%$ solution of Na-EDTA, cut in sections of $10 \mu$ and stained by a Masson's trichromic stain, by haemalum and eosin, or by orcein.

The microradiographic study of the three cases gives similar results. Fig. 7 corresponds to the entire thickness of the metaphysial wall of the ulna in Case 1. On the left side of this picture an almost continuous osseous plate lines the medullary cavity. On the right side, individual 


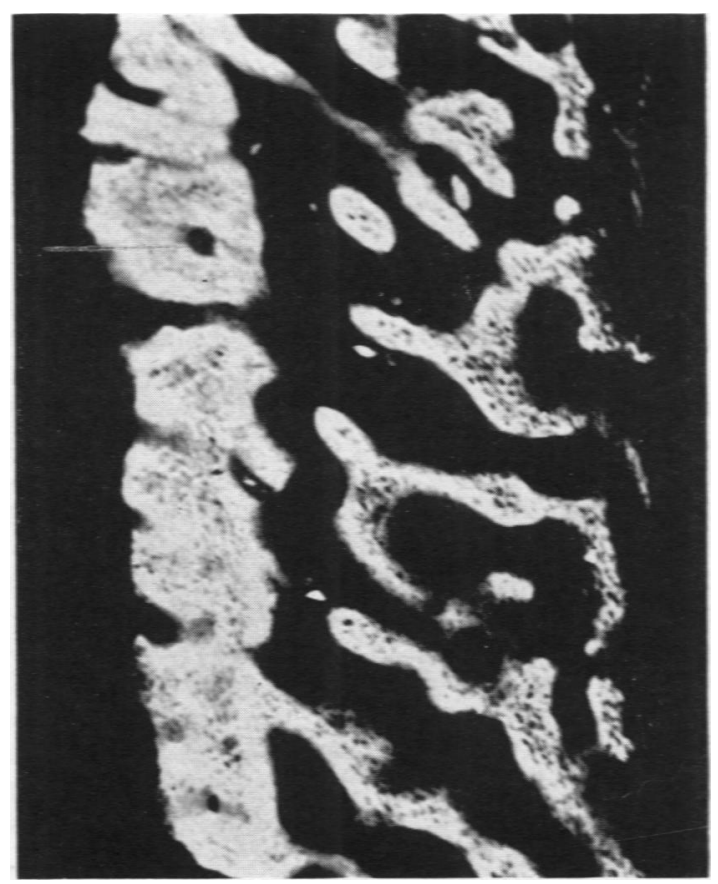

FIG. 7.-Case 1: microradiogram (negative) showing osseous plate lining the marrow cavity (left) and irregular subperiosteal trabeculae with enlarged osteocyte lacunae (right). ( $\times$ 51.)

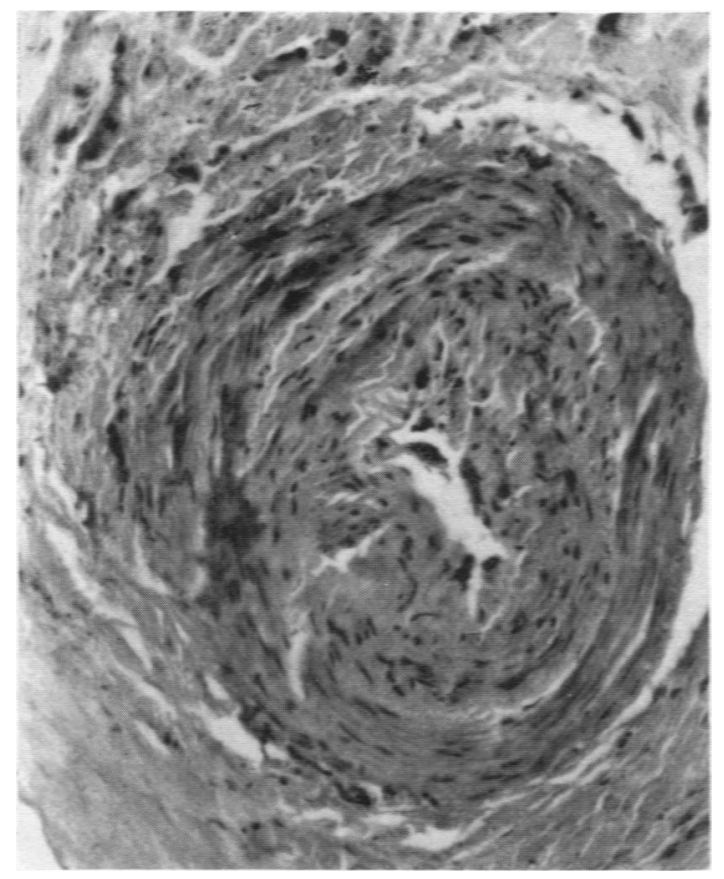

FIG. 8.-Case 2: proliferation of the intimal layers of an artery. (Haemalum and eosin. $: 235$.) trabeculae are obliquely attached under the periosteum (not visible in reproduction). Most of the trabeculae are abnormally eroded and show a jagged outline, together with notably enlarged osteocytic lacunae. This suggests a process of rapid bone resorption.

Sections from Case 1 provided some suggestive evidence of bone destruction, mostly beneath the periosteum. A striking and unexpected finding is the absence of osteoclasts. Some bone cells seem to have widened their lacunae. In the intertrabecular spaces there is a finely fibrillar connective tissue. This medullary tissue is very poor in cellular elements, and there is no inflammatory infiltration. The capillaries are noticeably dilated.

Vascular lesions are much more prominent in Case 2. Most of the arteries show a proliferation of the intimal layers, leading to progressive obliteration of the lumen (Fig. 8). Specific staining for elastin demonstrates conspicuous fragmentation of the elastic plates in the arterial walls. The fibrous reaction is also much more developed than in Case 1, and the enlarged small vessels are surrounded by a dense network of collagen bundles. While some trabeculae are being resorbed, others are covered by a chondroid tissue that seems to result from a progressive metaplasia of the fibrous tissue.

While occasional lacunae are empty in the sections from Case 2, in Case 3, where a later stage of the disease is seen, numerous bone areas are dead. These areas may be sequestrated, surrounded by leucocytes, mainly lymphocytes, and sharply isolated from the normal marrow by a definite capsule. More often, new osseous tissue is directly laid down against the dead bone remaining as a support. Regeneration can also occur through the transformation of fibrous tissue into chondroid and then into osseous tissue. In the final stages there is a general return of normal bone marrow tissue and disappearance of the obliterative arteritis.

The microscopic features may be summarized as follows. In Cases 1 and 2, biopsied respectively six weeks and one month after the first signs of osteo-articular involvement, vascular lesions are predominant, consisting of dilatation of the capillaries and thickening of the arterial walls. There is also fibrosis and early signs of bone resorption. In Case 3, biopsied after 15 months, bone necrosis resulting in sequestration predominates. New bone formation occurs, either by metaplasia of connective tissue or by creeping substitution.

\section{Discussion}

Confronted with an osteoarthritis occurring after smallpox, it is tempting to ascribe this to bacterial superinfection; the disease is severe and debilitating, and the very common secondary infection of the skin lesions might easily lead to metastatic bone infection. In fact, secondary pyogenic osteomyelitis seems to be infrequent in smallpox, as demonstrated by Bras (1952) in a large series of necropsies of smallpox cases. Moreover, the skeletal involvement appearing in the recovery period of smallpox presents distinctive features 
allowing it to be separated from bacterial osteomyelitis. The most important features of osteomyelitis variolosa, drawn mostly from the comprehensive review on the subject by Cockshott and MacGregor $(1958,1959)$ and from the recent paper by Davidson and Palmer (1963) are as follows.

Osteomyelitis variolosa affects roughly $0 \cdot 25$ $0 \cdot 50^{\circ}{ }_{0}^{\prime}$ of patients in a smallpox epidemic. The great majority of the cases occurs in children less than 5 years old. Protein malnourishment and anaemia may be predisposing factors. In most cases, the first signs of osteo-articular involvement do not appear before the smallpox exanthem is already healing. First to be noted is usually a diffuse periarticular swelling with tenderness and limitation of movements, most frequently involving the elbows. In the majority of cases the joint lesions become bilateral and multiple, causing severe functional incapacity. Next in frequency to the elbows are the wrists and hands, and the ankles, feet, and knees. The limbs in the vicinity of the involved joints may become grossly swollen. There are usually signs of fluid within the joints. Sinuses may occur, discharging serous or purulent material. Guarnieri bodies have been found in the joint fluid, which has most often been found to be sterile. Bacteriological cultures may, however, yield pyogenic organisms, such as cocci and salmonellae, especially after the appearance of sinuses.

Systemic manifestations are usually slight. Low grade fever and moderate leucocytosis have been observed but are usually absent. The evolution is that of a slow spontaneous recovery over the course of several weeks or months. Late sequelae may be important. They appear progressively and consist of reduction of longitudinal growth of bones with distortion, ankylosis, flail joints, and secondary osteoarthritis. Antibiotics do not seem to influence the course of the disease.

Radiologically the main features are: transverse bands of juxtametaphysial osteoporosis, often very marked periosteal reaction, less frequently extensive patchy destruction of the shafts of the long bones, followed by sclerosis. Detachment or sequestration of the epiphyses may occur and later cause severe growth disturbances.

There is no doubt that osteomyelitis variolosa deserves to be separated, clinically and radiologically, from ordinary pyogenic osteomyelitis, and it seems appropriate to make the same distinction in the field of pathogenesis, ascribing the bone lesions to the direct influence of the smallpox virus itself. There is, however, no definite proof for this, smallpox virus never having been isolated from the bone. Moreover, viral bone lesions in general seem to be rare.
Smallpox vaccination can be followed by bone lesions and the vaccinia virus has been identified in three of these cases (Sewall, 1949; Barbero, Gray, Scott, and Kempe, 1955; Cochran, Connolly, and Thompson, 1963), but the existing lesions are usually very circumscribed and lack the symmetric distribution seen in osteomyelitis variolosa (Elliott, 1959). Localized osteolytic lesions have been reported in cat-scratch disease by Adams and Hindman (1954) and Collipp and Koch (1959). In lymphogranuloma venereum, the causative organism of which is immunologically related to the virus of cat-scratch disease, arthritis and bone necrosis have been described by Wright and Logan (1939). However, these lesions bear no resemblance to those occurring after smallpox. It has been suggested by Delano and Butler (1947) that infantile cortical hyperostosis might also be due to a viral agent, though Caffey (1961) states that 'osteitis due to viral infections has not been conclusively proved'.

The osteitis seen in sickle-cell anaemia and mostly due to salmonellae may present some radiological similarity with osteitis variolosa. The exuberant periostitis and the osteolytic lesions of the diaphyses have often a rather similar aspect in both diseases, which also share the symmetrical distribution of their lesions. It may be of some significance that salmonellae, which only exceptionally give rise to skeletal infections except in sickle-cell anaemia, have also been found in articular fluid of osteomyelitis variolosa cases (J. Demoor, 1962, personal communication). In this context, sickle-cell anaemia may be excluded in our 3 patients, who were all homozygous for haemoglobin A.

The histological lesions found in our patients may provide some new evidence about the aetiology of osteomyelitis variolosa. It seems impossible to ascribe those lesions to bacterial infection: in bacterial osteomyelitis, empty cell lacunae and replacement of the marrow by purulent exudate would be found. In our cases, the intertrabecular space is not invaded by inflammatory cells, but by fibrous tissue. The generalized arteritis shown in our Case 2 does not exist in bacterial osteomyelitis, and might well be the fundamental lesion and the cause of the bone abnormalities. Indeed, our histological findings compare very closely with the effects of experimental ischaemia of the bone, as described by Rutishauser, Rohner, and Held (1960).

After partial occlusion of the arterial vessels in the bones of rabbits, these authors have observed widening of the sinuses, invasion of fibrous tissue bone necrosis, and 'fibrös-knorpelige Markmetaplasie', lesions very similar to those presented by our patients.

Because of the suggested viral aetiology of infantile 
cortical hyperostosis, it is interesting to note that some consider obliterating intimal proliferation as being the primary change in this disease (Sherman and Hellyer, 1950; Sidbury and Sidbury, 1954). As for the occurrence of bone infections due to salmonellae in both sickle-cell anaemia and osteomyelitis variolosa, it may be argued that both conditions have in common some degree of osseous hypoxaemia.

To conclude, histological as well as clinical and radiological appearances are against a bacterial aetiology of osteomyelitis variolosa. It seems unlikely that bone tissue as such is sensitive to the smallpox virus. The primary lesion seems to be a proliferating arteritis. Fibrosis, bone resorption, and necrosis could possibly proceed from the poor blood supply.

\section{Summary}

Clinical, radiological, and histological findings in three cases of osteomyelitis variolosa are described. The primary bone lesion is a proliferating arteritis, leading to fibrosis, necrosis, and bone resorption. A bacterial aetiology is unlikely.

We are grateful to Professor Hennebert and Dr. Traça of the Surgical Department of the Lovanium University Hospital who assumed the surgical responsibility for our patients and gave us access to their files; to Professor Vandepitte (Lovanium), Dr. Delville (Elisabethville), and Dr. Demoor (Léopoldville), who performed the bacteriological and virological examinations; to Professor Drexler (Lovanium) for the radiological examinations; and to Professor Hubble (Birmingham) and Dr. M. MacGregor (Warwick) for reading the manuscript.

\section{REFERENCES}

Adams, W. C., and Hindman. S. M. (1954). Cat-scratch disease associated with an osteolytic lesion. J. Pediat., 44, 665.

Barbero. G. J.. Gray, A.. Scott. T. F. M.. and Kempe. C. H. (1955). Vaccinia gangrenosa treated with hyperimmune vaccinal gamma globulin. Pediatrics, 16. 609.

Bras, G. (1952). The morbid anatomy of smallpox. Docum. Med. geogr. trop. (Amst.). 4. 303.

Caffey, J. (1961). Pediatric X-ray Diagnosis, 4th ed. Year Book Publishers. Chicago.

Cochran. W.. Connolly. J. H., and Thompson. I. D. (1963). Bone involvement after vaccination against smallpox. Brit. med. J., 2. 285 .

Cockshott, P.. and MacGregor. M. (1958). Osteomyelitis variolosa. Quart. J. Med., 27. 369.

- (1959). The natural history of osteomyelitis variolosa. J. Fac. Radiol. (Lond.). 10. 57.

Collipp, P. J., and Koch, R. (1959). Cat-scratch fever associated with an osteolytic lesion. New Engl. J. Med., 260. 278.

Davidson. J. C.. and Palmer. P. E. S. (1963). Osteomyelitis variolosa. J. Bone Jt Surg., 45-B, 687.

Delano. P. J., and Butler. C. D. (1947). The etiology of infantile cortical hyperostoses. Amer. J. Roentgenol., 58, 633.

Elliott, W. D. (1959). Vaccinial osteomyelitis. Lancet, 2, 1053.

Rutishauser, E.. Rohner. A., and Held. D. (1960). Experimentelle Untersuchungen über die Wirkung der Ischämie auf den Knochen und das Mark. Virchow's Arch. path. Anat., 333, 101.

Sewall. S. (1949). Vaccinia osteomyelitis; report of a case with isolation of vaccinia virus. Bull. Hosp. Jt Dis. (N.Y.), 10, 59.

Sherman. M. S., and Hellyer. D. T. (1950). Infantile cortical hyperostosis. Amer. J. Roentgenol., 63. 212.

Sidbury. J. B., Jr.. and Sidbury, J. B. (1954). Infantile cortical hyperostosis. New Engl. J. Med., 250. 309.

Wright. L. T.. and Logan, M. (1939). Osseous changes associated with lymphogranuloma venereum. Arch. Surg., 39, 108. 